\title{
FORMAÇÃO DE PROFESSORES PARA INCLUSÃO ESCOLAR NA MODALIDADE DE EDUCAÇÃO DE JOVENS E ADULTOS: ANÁLISE DE PESQUISAS
}

\author{
FORMACIÓN DE PROFESORES PARA INCLUSIÓN ESCOLAR EN LA \\ MODALIDAD DE EDUCACIÓN DE JÓVENES Y ADULTOS: ANÁLISIS DE \\ INVESTIGACIONES
}
TEACHER TRAINING FOR SCHOOL INCLUSION IN THE MODALITY OF YOUTH AND ADULTS EDUCATION: ANALYSIS OF RESEARCH

Maria do Carmo Lobato da SILVA ${ }^{1}$

Juliane Ap. de Paula PEREZ CAMPOS ${ }^{2}$

RESUMO: Esta pesquisa de revisão sistemática buscou descrever e analisar dissertações e teses que tematizassem sobre a formação inicial e continuada de professores para inclusão escolar de alunos com deficiência na modalidade da EJA, no período de 2008 a 2016, disponibilizadas no banco de Biblioteca Digital de Teses e Dissertações Brasileiras (BDTD) e Banco de Dissertações e Teses da Capes. Os descritores foram: formação de professores, formação docente, inclusão escolar, educação inclusiva, educação especial, deficiência, educação de Jovens e Adultos. Foram selecionadas nove produções para análise de conteúdo. Os resultados apontaram que três estudos focalizaram a concepção de professores sobre seu processo de formação inicial e continuada, indicando-os insuficientes e frágeis para atuar com alunos com deficiência na EJA; quatro indicaram que a formação continuada precisaria ocorrer no cotidiano da escola para atender as necessidades dos professores em serviço e dois estudos sinalizaram o trabalho colaborativo como estratégia para melhoria da formação dos professores. Evidenciou-se que a temática, formação de professores para inclusão escolar na modalidade de EJA, tem sido pouco privilegiada nas produções que dialogam a interface entre EJA e Educação Especial, tornando oportuno seu debate para o avanço de conhecimentos e discussão sobre a (re)estruturação de currículos de cursos de licenciaturas e reconfiguração de programas para a formação continuada.

PALAVRAS-CHAVE: Formação de professores. Educação especial. Educação de jovens e adultos.

RESUMEN: Esta investigación de revisión sistemática busca describir y analizar disertaciones y tesis que abordan la formación inicial y continuada de profesores para

${ }^{1}$ Universidade Federal de São Carlos (UFSCAR), São Carlos - SP - Brasil. Doutoranda em Educação Especial pelo Programa de Pós-Graduação em Educação Especial. Integrante do Grupo de Formação de Recursos Humanos em Educação Especial (GP-FOREESP). ORCID: <http://orcid.org/0000-0003-01855329>. E-mail: marialobato1607@gmail.com

2 Universidade Federal de São Carlos (UFSCar), São Carlos - SP - Brasil. Professora adjunta do Departamento de Psicologia. Doutora em Educação Especial e - Licenciatura em Educação Especial da Universidade Federal de São Carlos (UFSCar). Docente responsável pelo Grupo de Estudos e Pesquisas sobre a Escolarização da Pessoa com Deficiência (GEPEPD). ORCID: <https://orcid.org/0000-0003-0789808X>. E-mail: jappcampos@gmail.com

RPGE- Revista on line de Política e Gestão Educacional, Araraquara, v. 22, n. 3, p. 1154-1167, set./dez., 2018. E-ISSN: 1982-5587. 
conseguir la inclusión escolar de alumnos con discapacidad en la modalidad de la EJA, en el período de 2008 a 2016,y que están disponibles en el banco de la Biblioteca Digital de Tesis y Disertaciones (BDTD) y em el Banco de Disertaciones y Tesis de la Capes. Los descriptores fueron: formación de profesores, formación docente, inclusión escolar, educación inclusiva, educación especial, discapacidad y educación de Jóvenes y Adultos. Se seleccionaron nueve producciones para elanálisis de su contenido. Los resultados apuntaron tres estudios que enfocaron la visión delos profesores sobre sus proceos de formación inicial y continuada,mostrándolos insuficientes e inadecuados para actuar con alumnos con discapacidad en la EJA; cuatro indicaron que la formación continuada necesita ocurrir en el cotidiano de la escuela para atender a las necesidades de los profesores en servicio y dos estudios señalaron el trabajo colaborativo como estrategia para la mejora de la formación de los profesores. Se evidenció que la temática de formación de profesores para la inclusión escolar en la modalidad de la EJA ha sido poco privilegiada en las producciones que tratan sobre la conexión entre la EJA y la Educación Especial, haciendo oportuno su debate para el avance de conocimientos y la discusión sobre la (re) estructuración de currículos de cursos de licenciaturas y la reconfiguración de programas para la formación continuada.

PALABRAS CLAVE: Formación de profesores. Educación especial. Educación de jóvenes y adultos.

ABSTRACT: This systematic review seeks to describe and analyze dissertations and theses that focus on initial and continuing teacher training for inclusion of students with disabilities in the EJA modality, from 2008 to 2016, available at the Digital Library of Theses and Dissertations (BDTD) and Bank of Dissertations and Thesis of Capes. The descriptors were teacher training, school inclusion, inclusive education, special education, disability, youth and adult education. Nine productions were selected for content analysis. The results pointed out three studies that focused the conception of teachers on their initial and continuous formation process, indicating them insufficient and fragile to work with students with disabilities in the EJA; four studies indicated that continuing education needs to occur in the daily life of the school to meet the needs of the teachers in service and two studies indicated the collaborative work as a strategy to improve teacher training. It was evidenced that the thematic teacher training for school inclusion in the EJA modality has been underprivileged in the productions that dialogue the interface between EJA and Special Education, making it opportune its debate for the advancement of knowledge and discussion on the (re) structuring of curriculums of graduation courses and reconfiguration of programs for continuing education.

KEYWORDS: Teacher training. Special education. Education for youth and adults.

\section{Introdução}

A trajetória da Educação de Jovens e Adultos (EJA), no Brasil, tem sido marcada por processos historicamente excludentes. Os sujeitos da EJA, vistos como subalternizados, foram marginalizados dos processos escolares, traduzindo-se na marca 
mais inocultável da barbárie provocada pelo paradigma social hegemônico que se mantém e produz pela lógica da exclusão (DI PIERRO, 2008).

Os estudos de Soares et al. (2011) indicaram a falta de prioridade conferida à modalidade de EJA nas políticas, resultando na falta de investimentos, condições estruturais e pedagógicas, além do silenciamento da formação de professores para atender esta especificidade. A modalidade de EJA no ensino regular é um espaço privilegiado, com potencial para atender as necessidades específicas desta faixa etária e um ambiente ideal para prover a continuidade da aprendizagem escolar e desenvolvimento humano de todos aqueles que, por qualquer motivo, tenham sido excluídos da escola, inclusive jovens e adultos com deficiência. Constitui-se como um desafio pedagógico e político articular a modalidade de EJA ao público da Educação Especial.

Nos estudos de interface entre EJA e Educação Especial, Siems (2012) mapeou a produção acadêmica nos programas brasileiros de Pós-Graduação no período de 2003 e 2009. Foram localizadas dez dissertações e uma tese. Os resultados indicaram a fragilidade das estruturas pedagógicas da EJA para o atendimento educacional especializado (AEE) para as pessoas com deficiência e as dificuldades vivenciadas nos serviços especializados em oferecer condições para o desenvolvimento de atividades acadêmicas.

Brito e Campos (2013) focalizaram as produções sobre a escolarização de alunos com deficiência intelectual na EJA, no período de 1988 a 2008, em programas de PósGraduação em Educação, disponíveis no sistema de periódico da Coordenação de Aperfeiçoamento de Nível Pessoal Superior (CAPES). Dos resumos analisados, as temáticas principais incidiram sobre a alfabetização de jovens e adultos com deficiência intelectual e suas trajetórias escolares. As autoras indicaram a necessidade de aprimoramento das práticas pedagógicas para se atuar com este público na EJA.

Haas (2015), ao apresentar os direcionamentos legais e políticos nacionais acerca da Educação Especial na perspectiva da Educação Inclusiva na EJA, com base na produção sistematizada pelos encontros nacionais e regionais realizados pelo Fórum EJA e nas pesquisas realizadas na última década (2000-2012), ratificou o que tinha sido sinalizado por Siems (2012) sobre a timidez de estudos sobre o AEE para os jovens e adultos com deficiência, bem como a fragilidade deste atendimento no contexto da EJA.

Nesta mesma linha, os resultados de Trentin (2016) dialogaram com os estudos anteriores, reafirmando a predominância de relatos acerca da fragilidade das estruturas na EJA para pessoas com deficiência, bem como as dificuldades vivenciadas para oferecer 
atividades acadêmicas efetivamente enriquecedoras e eficazes para a inclusão destes jovens e adultos.

As pesquisas apontadas situam histórico e socialmente o debate sobre a interface EJA e Educação Especial, indicando que a preocupação maior nas produções acadêmicas analisadas, desde 1988 a 2015, envolveu a descrição, predominantemente, das situações socioeducacionais em que os sujeitos jovens e adultos com deficiência "permanecem" na condição de excluídos, por exemplo, dentro do ambiente escolar com ausência de adaptações curriculares para apropriação do conhecimento, ausência de AEE e, numa dimensão mais ampla, desassistidos por políticas públicas.

Siems (2012) e Haas (2015) verificaram a necessidade de novas pesquisas que englobassem os meios de aquisição de conhecimentos por parte de jovens e adultos com deficiência intelectual; os impactos de estratégias pedagógicas no desenvolvimento de indivíduos com deficiência; os estudos sobre a própria concepção dos sujeitos com deficiência sobre seus processos educativos, do AEE e a necessidade do debate sobre o trabalho pedagógico para viabilizar a inserção social e no trabalho de jovens e adultos com deficiência, além de estudos que focalizem a (re)configuração do AEE na modalidade da EJA. Sinalizaram, ainda, para o aprofundamento do debate sobre a formação de professores para atuarem com o Público Alvo da Educação Especial na modalidade de EJA, visto que historicamente tem ocorrido um processo de desprofissionalização e desvalorização da docência na modalidade da EJA e na educação especial. Para Glat e Pletsch (2011), a formação de professores é um dos pontos críticos que podem influenciar na efetivação das políticas educacionais e consolidação de inclusão escolar em qualquer nível e/ou modalidade escolar.

Para Dorziat (2011), a formação de professores para atender os alunos com deficiência na modalidade da EJA apresenta-se como um desafio constante, visto que sua formação foi direcionada a um tipo de aluno e com um perfil profissional para o primeiro segmento do Ensino Fundamental. A partir disto, tem-se como questionamento: como as produções acadêmicas vinham descrevendo a formação inicial e continuada de professores para atuarem na inclusão escolar de alunos com deficiência na modalidade da EJA?

O presente estudo objetivou descrever e analisar como as produções científicas tematizaram sobre a formação inicial e continuada de professores para atuarem na inclusão escolar de alunos com deficiência na modalidade da EJA. 


\section{Método}

Este estudo caracterizou-se como uma revisão sistemática que consiste em reunir e avaliar de forma crítica-reflexiva e sintética os resultados de uma multiplicidade de estudos a partir do objeto pesquisado. Costa e Zoltowski (2014) indicam que tal tipo de estudo potencializa as buscas, à medida que possibilita encontrar qualitativamente resultados de estudos de uma maneira organizada.

A escolha pela análise de teses e dissertações em bancos digitais deu-se por entender que esta modalidade de literatura, além de ser acessível gratuitamente, permitiria avanços nos estudos de interface (Educação Especial, Educação de Jovens e Adultos e Formação de Professores) tanto pelo fato de produzir conhecimentos inovadores quanto constituir bases para outros tipos de estudos.

\section{Procedimentos de Coleta de dados}

As informações foram obtidas no banco de dados disponível online da Biblioteca Digital de Teses e Dissertações Brasileiras (BDTD) ${ }^{3}$ e Banco de Dissertações e Teses da Capes $^{4}$ entre os anos 2008 e 2016. O foco da pesquisa incidiu sobre a formação de professores para inclusão escolar de alunos com deficiência na modalidade da EJA. O período delimitado foi em razão da primeira e última produção encontrada estar de acordo com o foco da pesquisa. A coleta de dados ocorreu no mês de outubro de 2017.

A busca foi realizada com a combinação dos seguintes descritores, seguido de operadores booleanos (AND, OR, parênteses), com o propósito de compor uma string para tornar exequível a busca: Formação de professores, Formação docente, Inclusão escolar, Educação inclusiva, Educação Especial, Deficiência, Educação de Jovens e Adultos. Foram incluídos os estudos que apresentaram a combinação dos descritores em seus títulos, palavras-chave e os resumos que apresentaram o foco sobre formação de professores para atuarem com alunos com deficiência na modalidade da EJA. Foram excluídos os estudos que tratavam de formação de professores para inclusão escolar e/ou Educação Especial na Educação Infantil, anos iniciais do Ensino Fundamental regular, estudos sobre formação de professores para modalidade da EJA que não tratavam do Público Alvo da Educação Especial e os replicados.

\footnotetext{
${ }^{3}$ Disponível em: http://bdtd.ibict.br/vufind/

${ }^{4}$ Disponível em: http://bancodeteses.capes.gov.br/
} 
Na primeira busca foram identificadas 318 produções, 238 dissertações, das quais 232 foram excluídas (99 replicadas e 133 fora do foco desta pesquisa) e seis foram incluídas por atender o objetivo desta pesquisa. Foram localizadas 80 teses, das quais 77 foram excluídas (46 replicadas e 31 fora do foco desta pesquisa), três foram incluídas.

As produções selecionadas foram lidas e analisadas descritivamente quanto ao ano de publicação, ao objetivo, aos participantes, ao tipo de abordagem, aos instrumentos ou às técnicas de coleta e aos resultados principais.

\section{Procedimento de análise dos dados}

Para as reflexões críticas sobre as produções científicas selecionadas, norteou-se a análise de conteúdo. Para Bardin (1977), a análise de conteúdo é um conjunto de técnicas de análise das comunicações que visa obter, por meio de procedimentos sistemáticos e análise objetiva, a descrição do conteúdo das mensagens e indicadores que permitam a inferência de conhecimentos relativos às condições de produção destas mensagens. A análise na íntegra das teses e dissertações possibilitou a sistematização de três categorias.

\section{Resultados e Discussão}

Os nove estudos analisados foram classificados em relação ao ano de defesa. Constatou-se que um foi finalizado em 2008, um em 2010, dois em 2011, um em 2012, dois em 2013, um em 2014 e um em 2016, conforme demonstrado no Quadro 1:

Quadro 1 - Pesquisas sobre a temática formação de professores para a modalidade de EJA com alunos com deficiência

\begin{tabular}{|c|c|c|c|}
\hline Ano & Dissertação & Tese & Total \\
\hline 2008 & 1 & - & 1 \\
\hline 2010 & - & 1 & 1 \\
\hline 2011 & 2 & - & 2 \\
\hline 2012 & - & 1 & 1 \\
\hline 2013 & 2 & - & 2 \\
\hline 2014 & 1 & - & 1 \\
\hline 2016 & - & 1 & 1 \\
\hline Total & $\mathbf{6}$ & $\mathbf{3}$ & $\mathbf{9}$ \\
\hline
\end{tabular}

Fonte: Biblioteca Digital de Teses e Dissertações (http://bdtd.ibict.br/); Coordenação de Aperfeiçoamento de Pessoal de Nível Superior (http://www.capes.gov.br/).

Quanto ao local da defesa das pesquisas, foram, predominantemente, em Programas de Pós-Graduação em Educação: duas foram desenvolvidas em instituições localizadas no estado do Pará (dissertações), duas no Rio Grande do Norte (uma dissertação e uma tese), 
uma em Pernambuco (dissertação), uma no Rio Grande do Sul (tese), uma em São Paulo (tese) e duas no Rio de Janeiro (dissertações, sendo uma no Programa de Pós-Graduação em Letras), o que nos permitiu conhecer como a temática sobre a formação de professores para atuar na modalidade de Educação de Jovens e Adultos com deficiência vinha sendo pouco debatida em programas de pós-graduação no Brasil.

Em relação às abordagens de pesquisas, os estudos de natureza qualitativa foram predominantes, com pesquisa participante (cinco dissertações), estudo de caso (uma dissertação e uma tese) e pesquisa colaborativa (duas teses). De modo geral, os objetivos dos sete estudos foram caracterizados como analíticos e descritivos e dois descritivos e interventivos. Predominantemente, os instrumentos utilizados para a coleta de dados foram a combinação de observações participantes e entrevistas semiestruturadas (cinco dissertações e três teses), uma dissertação utilizou somente a entrevista semiestruturada. Os registros foram feitos por meio de diários de campo, filmagens, fotografias e audiogravações. Em relação à análise dos dados, a maioria dos trabalhos realizou análise de conteúdo, outros fizeram análise do discurso.

Após a leitura e análise de conteúdo das produções que compuseram esta revisão, emergiram três categorias que descreveram os resultados: i) Concepção sobre formação inicial e continuada para inclusão escolar na modalidade da EJA; ii) Necessidade de formação continuada em serviço para atuação na EJA com PAEE e iii) Formação de professores no contexto de práticas colaborativas para inclusão na EJA.

\section{Concepção sobre formação inicial e continuada para inclusão escolar na modalidade da EJA}

As investigações aqui apresentadas apontaram as concepções dos professores sobre seu processo de formação inicial e continuada para atuarem com o PAEE na EJA. Lins (2011) identificou as concepções dos professores sobre inclusão durante o seu processo de formação e como se traduziam as propostas para a sala de aula na EJA, na qual os alunos com deficiência também fazem parte. A pesquisa contou com dezoito professores e seus coordenadores envolvidos num programa de formação continuada ofertado pela prefeitura de Recife/PE. Os dados foram obtidos por meio de entrevistas semiestruturadas e análise documental das propostas locais de políticas pedagógicas da EJA. Constatou-se que, na concepção dos professores, havia carência de suporte teórico e metodológico (disciplinas, conteúdos, metodologia e estratégias de ensino) nos cursos de licenciatura em pedagogia 
para atuarem com a inclusão de alunos com deficiência na modalidade EJA, refletindo-se nas dificuldades de alfabetizar estes alunos. E, na tentativa de solucionar a carência na formação inicial, os professores buscaram conhecimentos individualmente, cursando especializações e outros cursos para suprir suas necessidades.

Já Fernandes (2011) caracterizou a prática pedagógica e analisou, a partir da concepção de professores, o processo de formação do professor da EJA em uma classe especial. Os dados foram obtidos com duas professoras da classe especial e de Jovens e Adultos com diagnóstico de deficiência intelectual, síndrome de Down, Surdez e autismo. Verificou-se, a partir das falas dos professores, que o currículo do curso de pedagogia ofertado nas instituições de ensino do país, e em especial no Estado do Pará/PA, não atendiam às necessidades de formação do professor para EJA e para a escola inclusiva. Deste modo, os professores eram pressionados a buscarem constantemente aperfeiçoamento, entretanto, menos tempo era disponibilizado, devido à intensificação de carga horária do trabalho docente nas escolas do campo.

Dantas (2014), ao identificar as concepções de professores e alunos sobre os processos de escolarização de pessoas com deficiência intelectual na EJA e como repercutem no seu fazer pedagógico, constatou fragilidades nos processos de formação inicial para o atendimento do aluno com deficiência intelectual. Ao concluir, sinalizou que uma formação precária iria repercutir nas formas de conceber a aprendizagem e desenvolvimento destes alunos.

Foi possível visualizar, a partir dos resultados apontados por Lins (2011), Fernandes (2011) e Dantas (2014), que os professores, por meio de suas concepções, reconheciam a insuficiência de ações dirigidas à formação e atualização profissionais, demonstrando que havia certo consenso quanto ao fato de, em geral, ainda serem ínfimas as transformações nas práticas de ensino, assim como foram apontadas poucas melhorias na qualidade da aprendizagem dos alunos. Entre as razões que poderiam explicar tal situação, estaria o fato de que as ações de formação tendem a ter caráter pontual, ocorrem em períodos muito curtos e não partem da realidade das escolas e das necessidades dos docentes.

O foco das políticas de formação docente, ainda de forma insuficiente, prevalece na educação de crianças e adolescentes do primeiro segmento do ensino regular, acentuando maior fragilidade em relação ao investimento no ensino de jovens e adultos. Haas (2015) enfatizou que a formação de professores para EJA ocorre em âmbito geral e, em sua maioria, não fornecia base teórico-conceitual e práticas comprometidas com a inclusão, 
aprendizagem e desenvolvimento destes sujeitos, considerando a diversidade e as diferenças dos alunos nesta modalidade.

\section{Necessidade de formação continuada em serviço para atuação na EJA com PAEE}

Varella (2011) analisou as concepções atribuídas à inclusão e às práticas pedagógicas com jovens com paralisia cerebral, desenvolvidas por gestores e professores de uma escola que atuavam na modalidade de EJA na cidade do Natal/RN. O foco do estudo foi a articulação pedagógica entre professores da EJA, das ações das salas de recursos multifuncionais (SRMs) e a importância da formação continuada. Participaram da pesquisa quatro gestores e sete professoras. A coleta de dados foi realizada por meio da observação em sala de aula e na SRMs, entrevistas semiestruturas e aplicação de questionários. Constatou-se que a formação continuada precisaria ser parte de um processo contínuo e transversalizado pelo trabalho colaborativo junto aos alunos e à equipe de apoio. Neste processo, é função da coordenação pedagógica articular e mediar a formação em serviço, como também incluir em seus projetos e planos recursos destinados para este fim.

Melo (2013) identificou e analisou o que vinha sendo adotado como norma pelos professores junto aos discentes surdos na modalidade de EJA, permitindo o aperfeiçoamento/formação profissional em serviço. Participaram duas professoras do ensino regular da EJA que atuavam com alunos surdos e uma professora itinerante. Foi utilizado o instrumento SOSIA para obtenção de informações empíricas. Verificou-se que havia um sentimento de falta de orientação para realização do trabalho docente, no contexto da modalidade de EJA, com surdos. Melo (2013) indicou que as condições oferecidas, ou melhor, não oferecidas obrigavam o professor a produzir adaptações às normas ou mesmo a criá-las para possibilitar a alfabetização e letramento dos surdos.

Araújo (2013) analisou como uma escola de Ensino Fundamental, localizada na cidade de Altamira/ PA, promoveu a inclusão de estudantes com NEES na EJA. Dentre os aspectos, foram identificadas as necessidades educacionais pedagógicas e de formação dos professores que atuavam na EJA e na Sala de Recurso Multifuncional (SRM). Foi um estudo de caso que contou com nove professoras da modalidade da EJA que atuavam com alunos com NEES, uma professora da SRM, duas intérpretes, seis estudantes com deficiência, uma coordenadora da Educação Especial/Inclusiva do município e uma coordenadora da EJA da escola. A obtenção de informações foi realizada por meio das 
observações participantes e entrevistas semiestruturadas. Destacou-se que havia negligências nos processos de formação para atender às escolas, principalmente, as do campo. Houve também os profissionais que ressaltaram que aprendiam com as experiências vividas, ou seja, acessavam por conta própria tanto uma especialização na área da Educação Especial e Inclusiva ou na EJA. Assim, a formação para a inclusão ainda não constitui uma política prioritária da escola e do sistema educacional municipal.

Santos (2014) caracterizou a inclusão escolar de alunos com deficiência na Educação de Jovens e Adultos/EJA no CIEP José Pedro Varela, considerando a articulação entre a sala comum e AEE oferecido na SRMs. Ao pesquisar sobre as experiências de inclusão de alunos com deficiência na modalidade da EJA, problematizou a formação de professores. Participaram seis professores que atuavam com alunos jovens e adultos com deficiência incluídos na modalidade de EJA e um professor da SRMs. Foi realizada a observação participante e entrevistas semiestruturadas com os professores. Constatou-se a necessidade de formação continuada para atender, principalmente, todos os professores atuantes na rede pública de ensino e não somente aqueles atuantes com alunos com deficiência.

Santos (2014) enfatizou que a formação precisaria ampliar nos professores seu conhecimento cultural com potencial crítico, visto que a escola é um lócus no qual fluem pessoas com inúmeras diferenças e que precisam ter suas necessidades educacionais atendidas.

$\mathrm{Na}$ perspectiva de Capellini e Mendes (2004), a formação continuada de professores pautada em princípios inclusivos é necessária em qualquer nível ou modalidade de ensino. O paradigma da inclusão promove diferentes desafios a serem vencidos e impulsiona a produção de novos conhecimentos. Dentre tantos desafios, têm-se aqueles relacionados ao desconhecimento e à falta de preparação para lidar com a diversidade, especialmente aquela decorrente de necessidades específicas.

\section{Formação de professores no contexto de práticas colaborativas para inclusão na EJA}

Pires (2010) analisou e avaliou duas intervenções, a primeira dirigida a acadêmicos do curso de Letras (Espanhol) que objetivou formar um grupo de oito futuros professores para ensino do Espanhol na Educação Especial e a segunda foi dirigida a treze alunos com deficiência intelectual na modalidade de EJA e visou promover aprendizagens e desenvolvimento no grupo participante, a partir do ensino desta língua estrangeira (LE). 
Foi uma pesquisa colaborativa e as informações foram obtidas por meio da observação em sala de aula com registros em diário de campo, questionários com perguntas abertas, entrevistas semiestruturadas e análise dos trabalhos produzidos pelos dois grupos de sujeitos. Confirmou-se que a proposta de trabalho colaborativo contribuiu para a formação dos futuros docentes no sentido de superação do medo e da insegurança; desmistificação de preconceitos sobre pessoas com deficiência; entendimento da importância da colaboração, planejamento e papel do professor atuar como guia, bem como aprendizagem de língua espanhola pelos alunos com deficiência intelectual.

Já Ferreira (2016) analisou as possibilidades e os desafios de um trabalho colaborativo entre a Universidade e a Escola para a formação de professores de educação física, visando à promoção da inclusão escolar na modalidade de EJA. Participaram três acadêmicos do curso de Licenciatura em Educação Física da Universidade de Mato Grosso/MT e uma professora em exercício da rede estadual de ensino que lecionava no Ensino Fundamental e na EJA. Foram adotados procedimentos da pesquisa colaborativa, com encontros de formação e como instrumentos para obtenção de informações foram utilizados o questionário e uma entrevista semiestruturada. Os resultados indicaram que as experiências do trabalho colaborativo entre universidade (licenciandos) e a escola (professores e alunos), sem a determinação de uma hierarquia de saberes, possibilitaria condições para a melhoria da formação inicial e continuada dos professores, contribuindo com a produção de estratégias de ensino que promovam a igualdade de oportunidades para todos.

Mendes, Toyoda e Bisaccione (2007) enfatizaram a potencialidade da parceria colaborativa entre universidade e escola não só em processos de formação continuada, mas na formação inicial dos professores, visto que oportuniza experiências mais significativas em conjunto para tais profissionais em formação, além da contribuição por meio das intervenções planejadas e avaliadas pelo grupo colaborativo com a proposição curricular e vice e versa.

Neste contexto, os professores em formação buscam conhecimentos e intervenções pedagógicas para minimizarem ou superarem os problemas que enfrentam, possibilitando um ensino com maior qualidade. Para Otalara e Dall'acqua (2016) este processo de colaboração cria possibilidades e oportunidades significativas para se pensar a formação dos futuros professores, dos professores em exercício e, em especial, em práticas pedagógicas que aspiram incluir todos os alunos nas aulas em níveis e modalidades diferentes.

RPGE- Revista on line de Política e Gestão Educacional, Araraquara, v. 22, n. 3, p. 1154-1167, set./dez., 2018. E-ISSN: $1982-5587$. 


\section{Considerações finais}

O propósito da revisão sistemática foi o de descrever e analisar as dissertações e teses que tematizassem sobre formação de professores para inclusão escolar de alunos com deficiência na modalidade da EJA, no período de 2008 a 2016.

A partir da descrição e análise das pesquisas que enfatizaram a formação dos professores para atuarem na EJA com alunos com deficiência foi possível perceber que os estudos foram voltados para a concepção dos professores sobre seu processo de formação. Além disto, tais profissionais apontaram fragilidades na formação inicial e continuada, refletindo, assim, no processo de ensino e aprendizagem. Entretanto, ao mesmo tempo em que as pesquisas indicaram que os professores não se sentiam preparados para atuarem com este público na EJA, houve pesquisas que sinalizaram o trabalho colaborativo como estratégia que privilegiasse a melhoria da formação inicial e continuada dos professores.

A ausência de condições de ensino impostas atualmente pelas ineficientes políticas educacionais inclusivas tem reduzido o papel do professor a mero espectador do processo educacional de jovens e adultos com deficiência inseridos na modalidade da EJA, a medida que o professor não tem uma compreensão clara sobre o processo de aprendizagem e desenvolvimento das pessoas com deficiência.

Conclui-se que os estudos que envolvem processos de formação de professores para interface entre EJA e Educação Especial ainda são escassos, portanto, há necessidade de ampliar investigações com este foco, bem como ampliar o debate sobre (re)estruturação de currículos de cursos de licenciaturas e reconfiguração de programas para a formação continuada para atender a modalidade da EJA.

\section{REFERÊNCIAS}

\section{ARAÚJO, M. D. Tessituras da inclusão na Educação de Jovens e Adultos no} município de Altamira-Pará. 2013. 212f. Dissertação (Mestrado em Educação) Universidade do Estado do Pará, Belém, 2013.

BARDIN, L. Análise de conteúdo. Lisboa: Edições 70, 1977.

BRITO, J.; CAMPOS, J. A. P. P. Escolarização de Jovens e adultos com deficiência intelectual: considerações em Pesquisas em dissertações e teses de 1988 a 2008. Revista Educação Especial, v. 26, n. 45, p. 45-58, 2013. Disponível em:

http://www.ufsm.br/revistaeducacaoespecial. Acesso em: 12 dez. 2017.

CAPELLINI, V. L.; MENDES, E. G. Formação Continuada de Professores para a Diversidade. Educação, v. 54, n. 3, p. 597-615, 2004. 
COSTA, A. B., ZOLTOWSKI, A. P. C. Como escrever um artigo de revisão sistemática. In: KOLLER, M. C. P.; HOHENDORFF, J. V. C. (Orgs) Manual de Produçãa Científica. Porto Alegre: Penso, 2014. p. 55-70.

DANTAS, D. C. L. A inclusão de pessoas com deficiência intelectual na Educação de Jovens e Adultos (EJA): um estudo de caso. 2012. 288f. Tese (Doutorado em Educação). Universidade Federal do Rio Grande do Norte, Natal, 2012.

DI PIERRO, M. C. Luta Social e reconhecimento jurídico do direito humano dos jovens e adultos à educação. Educação. Santa Maria, v. 33, n. 3, p. 395-410, 2008. Disponível em: http//www.ufsm/revistaeeducação. Acesso em: 12 dez. 2017.

DORZIAT, A. A formação de professores e a educação inclusiva: desafios contemporâneos. In: CAIADO, K. R. M.; JESUS, D. M.; BAPTISTA, C. R. (Orgs.). Professores e Educação Especial: formação em foco. Porto Alegre: Mediação/CDV/FACITEC, 2011.

FERREIRA, A.R.A. Trabalho colaborativo na educação física escolar: estratégias para a formação de professores e inclusão. 2016. 169f. Tese (Doutorado em Educação).

Universidade Estadual Paulista, Presidente Prudente, São Paulo, 2016.

FERNANDES, A. P. S. Estudos e observações sobre vivências docentes da educação de jovens e adultos no processo de inclusão escolar. 2011. 145f. Dissertação (Mestrado em Educação). Universidade do Estado do Pará, Belém, 2011.

GLAT, R.; PLETSCH, M. D. Inclusão escolar de alunos com necessidades educacionais especiais. Rio de Janeiro: EdUERJ, 2011. 162p.

HAAS, C. Educação de jovens e adultos e educação especial: a (re) invenção da articulação necessária entre as áreas. Educação, v. 40, n. 2, p. 347-360, 2015. Disponível em: http://dx.doi.org/10.5902/198464449038. Acesso em: 09 nov. 2017

LINS, M. V. L. Formação docente na educação de Jovens e Adultos: processo de inclusão/exclusão de pessoas com necessidades educacionais especiais em uma perspectiva de humanização. 2008. 230f. Dissertação (Mestrado em Educação). Universidade Federal do Pernambuco, Recife, 2008.

MELO, R. F. A experiência como fonte de normas: o trabalho de professores da EJA com alunos surdos. 2013. 147f. Dissertação (Mestrado em Letras). Universidade do Estado do Rio de Janeiro, Rio de Janeiro, 2013.

MENDES, E. G.; TOYODA, C. Y.; BISACCIONE, P. S.O.S. Inclusão escolar: avaliação de um programa de consultoria colaborativa com base em diários de campo. In: JESUS, D. M.; BAPTISTA, C. R.; BARRETO, M. A. S. C.; VICTOR, S. L (Org.). Inclusão, praticas pedagógicas e trajetórias de pesquisa. Porto Alegre: Editora Mediação, 2007.

OTALARA, A. P.; DALL'ACQUA, M. J.C. Formação de professores para alunos públicoalvo da educação especial: algumas considerações sobre limites e perspectivas. Revista Ibero-Americana de Estudos em Educação, v. 11, n.2, p.1048-1058, 2016. Disponível em: https://dx.doi.org/10.21723/riaee.v11.esp2.p1048-1058. Acesso em: 09 nov. 2017 
PIRES, F. L. B. O ensino da Língua Espanhola na Educação Especial: Formação docente e aprendizagem de pessoas com Deficiência Intelectual. 2010. 257f. Tese (Doutorado em Educação). Universidade Federal de Pelotas, Pelotas, 2010.

SANTOS, T. M. D. Alunos com deficiência na Educação de Jovens e Adultos: experiências de inclusão na escola pública. 2014. 108f. Dissertação (Mestrado em Educação). Universidade Federal Fluminense, Rio de Janeiro, 2014.

SIEMS, M. E. R. Educação de jovens e adultos com deficiência: saberes e caminhos em construção. Eixo temático: Alfabetização e Educação de Jovens e Adultos. Revista Educação em foco, v. 16, n. 2, p. 61-79, 2012.

SOARES, L.; SILVA, F. R.; FERREIRA, L. O. F. A pesquisa em Educação de Jovens e Adultos: Um olhar retrospectivo sobre a produção do período de 1998 a 2008. In: SOARES, L. (Org.). Educação de Jovens e Adultos: O que revelam as pesquisas? Belo Horizonte: Autêntica Editora, 2011.

TRENTIN, V. B. Escolarização de jovens e adultos com deficiência nas pesquisas de pós-graduação no período de 2009 a 2015. Revista Educação Especial. v. 29, n. 55, p. 361-372, 2016. Disponível em: http://dx.doi.org/10. 5902/1984686X19693 362. Acesso em: 10 nov. 2017.

VARELLA, M. C.B. Trilhas da inclusão escolar percorridas por uma aluna com paralisia cerebral na EJA: concepções e práticas. 2011. 223f. Dissertação (Mestrado em Educação). Universidade Federal do Rio Grande do Norte, Natal, 2011.

\section{Como referenciar este artigo}

SILVA, Maria do Carmo Lobato da.; CAMPOS, Juliane Aparecida de Paula Perez. Formação de professores para inclusão escolar na modalidade de Educação de Jovens e Adultos: análise de pesquisas. Revista on line de Política e Gestão Educacional, Araraquara, v. 22, n. 3, p. 1154-1167, set./dez., 2018. E-ISSN: 1982-5587. DOI: 10.22633/rpge.v22i3.11391

Submetido em: 21/05/2018

Aprovado em: 23/08/2018 